\title{
RENAL TUBULAR SECRETION OF POTASSIUM IN MAN ${ }^{1}$
}

\author{
By ALEXANDER LEAF 2 ANd AUGUSTO A. CAMARA with THE TECHNICAL ASSISTANCE \\ OF BETH ALBERTSON
}

(From the Department of Internal Medicine, The Medical School, University of Michigan, Ann Arbor, Michigan)

(Received for publication June 20, 1949)

The work of Keith and Osterberg (1) and of others $(2-4)$ has demonstrated that "the concentration of potassium in the serum of a patient who has developed severe renal insufficiency may be normal, increased or diminished" (1). Such variability in serum potassium concentration might not have been predicted from a consideration of the known facts regarding potassium intake and excretion.

Natural foods are high in potassium content so that even the low protein diets recommended for patients with chronic renal insufficiency contain $50 \mathrm{mEq}$. (2.0 grams) or more daily. Hence, the amount of potassium requiring excretion to preserve balance is large, even in patients with severe renal insufficiency who are taking food. The major portion of ingested potassium normally appears in the urine. A failure on the part of the kidneys to clear the body of the major portion of ingested potassium daily would be expected to result in retention of potassium with increase in its concentration in the body fluids. Furthermore, potassium, like urea, is a substance which in the normal subject is excreted in the urine at concentrations considerably greater than its concentration in the extracellular fluids. Finally, and also like urea, the quantity of potassium found in the urine of normal subjects on usual levels of potassium intake is uniformly less than the quantity of potassium in the simultaneous volume of glomerular filtrate $(3,5,6)$, indicating that potassium, like urea, is normally reabsorbed partially through the renal tubular epithelium.

With the above considerations in mind, one might have anticipated that in patients with chronic renal insufficiency, an elevated concentration of serum potassium would be uniformly

\footnotetext{
1 Aided by a grant from the United States Public Health Service.

2 Present address: Massachusetts General Hospital, Boston.
}

found, just as the blood urea concentration is elevated. Elkinton et al. (3) stated that depression of the rate of glomerular filtration appears to be the principal limiting factor with respect to potassium excretion in renal insufficiency. But we have encountered patients with glomerular filtration volumes of about 5 liters in 24 hours with normal levels of serum potassium. These patients accordingly would have little more than $25 \mathrm{mEq}$. of potassium in the glomerular filtrate. Since they were ingesting considerably larger amounts, it seemed desirable to learn whether the patient with severe renal insufficiency utilizes renal mechanisms for excreting potassium not evident in the normal subject.

The purpose of this paper is to present evidence that renal tubular secretion of potassium may occur in severe renal insufficiency and constitutes a mechanism to prevent accumulation of potassium to toxic levels in the body fluids.

The renal tubular secretion of potassium has been demonstrated in the dog by Berliner and Kennedy (7). Their observations were made following preliminary preparation of the dogs with oral potassium chloride supplements and the intravenous administration of hypertonic potassium chloride during the clearance periods. With such preparation, ratios of excreted to filtered potassium varying from 0.49 to 1.33 were obtained. Mudge et al. (8) were likewise able to demonstrate potassium excretion in excess of the calculated amount filtered in dogs under light pentobarbital anesthesia during forced osmotic diuresis with urea, with or without exogenous potassium administration. Potassium clearance to creatinine clearance ratios as high as 1.36 were obtained when the creatinine urine to plasma ratio fell below 2 .

To our knowledge, evidence of renal tubular secretion of potassium in man has not been stressed previously. This possibility has been 
suggested by isolated observations $(3,9)$. However, the few published data are inconclusive.

\section{METHODS}

Four patients, H. R., D. M., D. P., and F. W., with severe chronic renal insufficiency were the subjects for this study. Their clinical histories are briefly described in the appendix. In three of them the diagnosis was chronic glomerulonephritis and in one patient, D. M., probably polycystic kidney disease. All patients were receiving a diet containing $\mathbf{4 0}$ grams of protein at the time of the studies and were given no medications except supplementary sodium and "Amphogel" in some instances. Those patients who felt well enough were permitted to be up and about the ward. In subject $F$. W., who was studied most intensively in our Metabolism Unit, the composition of the diet was more exactly known during the studies reported in Table II and is included in that table. The values for the potassium, sodium and chloride content of his diet were obtained from McCance and Widdowson (10). Values obtained from this source have been found to check surprisingly well with our own analyses (6). All the diet was eaten and, though bothered with nausea, the patient had only one small emesis during the study, three hours after the noon meal on April 15th.

Urine collections were made over 24 hour periods using toluene as preservative. Specimens were analysed separately on the day following collection. Fasting blood samples were obtained daily with a minimum of stasis. Samples for potassium were drawn under oil and the serum promptly separated from the cells with no hemolysis occurring. Refrigeration of the blood was found to be unnecessary.

Analytical methods used were the same as those previously reported from this laboratory (6). Potassium was determined in serum and urine by a modification of the platinic chloride micro-colorimetric method of Shohl and Bennett (11). All urine potassium determinations have been checked with our internal standard flame photometer (12), which gives results that check within $\pm 5 \%$ of the values obtained by the colorimetric method and with which recoveries of added potassium to urine are obtained with an average error of $\pm 1 \%$. Serum and urine creatinine determinations were made by the Bonsnes and Taussky (13) modification of the alkaline picrate method of Folin. All data reported are the averages of duplicate analyses which have checked within the limits of error of the respective method used.

Twenty-four hour urea and creatinine clearances were calculated by dividing the total 24 hour urine urea and creatinine contents by their respective fasting blood and serum concentrations (see discussion below for the validity of this calculation). All the creatinine and urea determinations were made by one of us (A. C.) who has had considerable prior experience with these techniques. As an additional check of the creatinine determinations the recently reported modification by Hare and Hare (14) was also used on a single serum and urine specimen. The Bonsnes and Taussky method gave a serum creatinine concentration of $14.5 \mathrm{mgs}$. per $100 \mathrm{cc}$. and a urine creatinine content of 0.618 grams. The values obtained with the Hare and Hare procedure were 14.9 mgs. per $100 \mathrm{cc}$. and 0.622 grams respectively.

Evidence has been presented to indicate that caronamide (4-carboxyphenylmethanesulfonanilide) is effective in blocking the tubular secretion of penicillin, phenol red, diodrast, and PAH (15). Brod and Sirota (16) have reported evidence that this substance blocked tubular secretion of endogenous creatinine chromogen in the single case they found to have an unusually high ratio of creatinine to inulin clearance. It was thought that perhaps caronamide might likewise be effective in blocking the tubular secretion of potassium in subject F. W. We were also interested to see if it might not produce a decrease in creatinine clearance as occurred in the single case of Brod and Sirota. For these reasons caronamide was administered in a dosage of $1.0 \mathrm{gram}$ every four hours from 9:00 a.m. on May 27th through 5:00 a.m. on May 29th. Considering the patient's very poor renal function this dosage was estimated to be adequate, though we have no proof that it was.

\section{RESULTS}

Table I shows data from our four nephritic patients obtained from random 24 hour clearance periods during their hospital stay. The value for "filtered" potassium is calculated as the product of the concentration of serum potassium and the 24 hour volume of the glomerular filtrate. The 24 hour clearance of endogenous creatinine is taken as the measure of the volume of glomerular filtrate in this calculation. The justification for using this measure of glomerular filtration rate and a single serum potassium concentration is discussed below.

That the actual 24 hour excretion of potassium considerably exceeds the quantity of potassium in the simultaneous volume of glomerular filtrate is indicated by the ratio of excreted to filtered potassium which is greater than 1.0. According to current concepts of renal physiology, the presence in the urine of a larger quantity of a substance than is contained in the simultaneous volume of glomerular filtrate is proof of tubular secretion of that substance. These considerations indicate that in our subjects tubular secretion was significantly contributing to the potassium excretion observed.

The single elevated serum potassium concentration, $7.72 \mathrm{mEq}$./liter, for subject D. M. was the result of the administration of large amounts of potassium several days prior to this study. In 
TABLE I

Data which indicate tubular secretion of potassium

\begin{tabular}{|c|c|c|c|c|c|c|c|c|}
\hline Subject & Date & $\begin{array}{c}\text { Serum } \\
\text { creatinine }\end{array}$ & $\begin{array}{l}24 \text { hour } \\
\text { creatinine } \\
\text { excretion }\end{array}$ & $\begin{array}{l}24 \text { hour } \\
\text { creatinine } \\
\text { clearance }\end{array}$ & $\underset{\mathbf{K}}{\text { Serum }}$ & $\begin{array}{c}\text { "Filtered" } \\
\mathbf{K}\end{array}$ & $\underset{\mathbf{K}}{\text { Excreted }}$ & $\begin{array}{c}\begin{array}{c}\text { Ratio } \\
\text { excreted }\end{array} \\
\text { filtered }\end{array}$ \\
\hline $\begin{array}{l}\text { H. R. } \\
\text { D. M. } \\
\text { F. W. } \\
\text { F. W. } \\
\text { F. W. } \\
\text { F. W. } \\
\text { D. P. } \\
\text { D. P. }\end{array}$ & $\begin{array}{l}1 / 6 / 49 \\
3 / 3 / 49 \\
2 / 18 / 49 \\
3 / 15 / 49 \\
3 / 17 / 49 \\
4 / 1 / 49 \\
5 / 9 / 49 \\
5 / 11 / 49\end{array}$ & $\begin{array}{l}\text { mgs. \% } \\
20.3 \\
10.8 \\
12.6 \\
12.3 \\
11.7 \\
9.8 \\
8.75 \\
8.75\end{array}$ & $\begin{array}{l}\text { grams } \\
0.763 \\
0.716 \\
0.508 \\
0.890 \\
0.889 \\
0.617 \\
0.701 \\
0.869\end{array}$ & $\begin{array}{l}\text { liters } \\
3.77 \\
6.63 \\
4.03 \\
7.24 \\
7.59 \\
6.33 \\
8.01 \\
9.93\end{array}$ & $\begin{array}{c}m E q / \text { liter } \\
4.19 \\
7.72 \\
5.29 \\
2.82 \\
3.49 \\
3.55 \\
4.30 \\
3.78\end{array}$ & $\begin{array}{c}m E q / 24 \text { hours } \\
15.8 \\
51.2 \\
21.3 \\
20.4 \\
26.5 \\
22.5 \\
34.4 \\
37.5\end{array}$ & $\begin{array}{c}m E q / 24 \text { hours } \\
20.4 \\
84.2 \\
31.4 \\
30.3 \\
36.5 \\
34.3 \\
43.4 \\
45.2\end{array}$ & $\begin{array}{l}1.29 \\
1.64 \\
1.47 \\
1.49 \\
1.38 \\
1.52 \\
1.26 \\
1.21\end{array}$ \\
\hline
\end{tabular}

"Filtered" $\mathrm{K}$ is the product of the creatinine clearance taken as a measure of glomerular filtration rate and the serum potassium concentration. The ratio of excreted to filtered potassium is the same as the potassium to creatinine clearance ratio. The fact that this ratio exceeds 1.0 indicates that in each 24 hour period more potassium was excreted than was present in the glomerular filtrate. Hence potassium was secreted by the tubules.

spite of the marked renal damage and a diet containing over $50 \mathrm{mEq}$. of potassium daily, he was able gradually to rid himself of this accumulated potassium so that the serum potassium concentration nine days later was $6.73 \mathrm{mEq}$./liter. The low serum potassium concentrations recorded for subject $\mathrm{F}$. W. were obtained at a time when the patient was having considerable nausea and vomiting and eating poorly. Subsequent serum potassiums on this subject, when he was eating well and not vomiting, were entirely normal-see Table II.

Because of these highly suggestive data, more detailed studies were undertaken on subject F. W. and the results are recorded in Table II. Here again the ratio of excreted to filtered potassium was found to exceed 1.0. The 24 hour clearance of urea is also recorded. Its relationship to the simultaneous clearance of endogenous creatinine supports the use of the latter as a measure of the volume of glomerular filtrate.

These studies on subject $F$. W. were done under carefully controlled conditions and while the subject was on a fixed diet containing $68.0 \mathrm{mEq}$. of potassium daily. Though potassium excre-

TABLE II

Repeated observations on Subject $F$. W. while on a fixed diet to show 24 hour creatinine and urea clearances, and "filtered" and excreted potassium

\begin{tabular}{|c|c|c|c|c|c|c|c|c|c|c|c|}
\hline \multirow{2}{*}{$\begin{array}{l}\text { Date } \\
1949\end{array}$} & \multicolumn{3}{|c|}{ Urea } & \multicolumn{3}{|c|}{ Creatinine } & \multicolumn{5}{|c|}{ Potassium } \\
\hline & $\begin{array}{l}\text { Blood } \\
\text { urea } \\
\text { nitrogen }\end{array}$ & $\begin{array}{l}24 \text { hour } \\
\text { urea N. } \\
\text { excretion }\end{array}$ & $\begin{array}{l}24 \text { hour } \\
\text { urea } \\
\text { clearance }\end{array}$ & $\underset{\text { creatinine }}{\text { Serum }}$ & $\begin{array}{l}24 \text { hour } \\
\text { creatinine } \\
\text { excretion }\end{array}$ & $\begin{array}{l}24 \text { hour } \\
\text { creatinine } \\
\text { clearance }\end{array}$ & $\underset{\mathbf{K}}{\text { Serum }}$ & $\begin{array}{c}\text { "Filtered" } \\
\mathbf{K}\end{array}$ & $\underset{\mathbf{K}}{\text { Excreted }}$ & $\frac{\text { Exc }}{\text { Fil }}$ & creted $\mathbf{~} \mathbf{\text { tered }}$ \\
\hline $\begin{aligned} \text { April } 12 \\
13 \\
14 \\
15 \\
16 \\
17 \\
17 \\
\text { May } 26 \\
27 \\
28 \\
29\end{aligned}$ & $\begin{array}{c}\text { mgs. \% } \\
150.6 \\
147.7 \\
148.2 \\
148.3 \\
141.2 \\
140.2 \\
117.1 \\
117.2 \\
119.8 \\
114.6\end{array}$ & $\begin{array}{l}\text { grams } \\
4.07 \\
5.73 \\
6.16 \\
5.72 \\
5.72 \\
\\
3.59 \\
3.14 \\
3.13\end{array}$ & $\begin{array}{l}\text { liters } \\
2.70 \\
3.65 \\
3.88 \\
4.15 \\
3.86 \\
\\
3.07 \\
3.69 \\
2.61\end{array}$ & $\begin{array}{c}\text { mgs. \% } \\
12.8 \\
12.5 \\
12.8 \\
12.2 \\
12.7 \\
12.7 \\
11.2 \\
11.2 \\
12.2 \\
13.2\end{array}$ & $\begin{array}{l}\text { grams } \\
0.758 \\
0.858 \\
0.840 \\
0.822 \\
0.811 \\
\\
0.552 \\
0.603 \\
0.605\end{array}$ & $\begin{array}{l}\text { liters } \\
5.92 \\
6.86 \\
6.59 \\
6.74 \\
6.39 \\
\\
4.94 \\
5.38 \\
4.96\end{array}$ & $\begin{array}{c}m E q / l \\
4.46 \\
\\
4.54 \\
4.60 \\
5.59 \\
5.27 \\
5.30\end{array}$ & $\begin{array}{c}m E q / 24 \text { hours } \\
26.4 \\
\\
29.9 \\
30.6 \\
29.4 \\
\\
27.6 \\
28.4 \\
26.3\end{array}$ & $\begin{array}{c}m E q / 24 \text { hours } \\
49.3 \\
54.7 \\
60.1 \\
56.5 \\
61.0 \\
47.1 \\
51.6 \\
52.5\end{array}$ & $\begin{array}{l}1.87 \\
2.01 \\
1.85 \\
2.07 \\
1.78 \\
1.82 \\
2.00\end{array}$ & $\begin{array}{l}\text { caron- } \\
\text { amide } \\
1.0 \\
\text { gram } \\
\text { every } 4 \\
\text { hours }\end{array}$ \\
\hline
\end{tabular}

Composition of diet during this study: Protein -41.3 grams, Calories-2320, Sodium-7.0 mEq., Chloride-16.0 $\mathrm{mEq}$. and Potassium-68.0 mEq.

The ratio of excreted to filtered potassium is the same as the potassium to creatinine clearance ratio. The fact that this ratio exceeds 1.0 indicates that in each 24 hour period more potassium was excreted than was present in the glomerular filtrate volume. Hence potassium was secreted by the tubules. Note that caronamide administration during the last two periods had no effect on potassium, creatinine, or urea excretions. 
tion by extra-renal routes was not measured in the present study, it is interesting to note that if the quantity of potassium excreted had been limited to the amount present in the glomerular filtrate, the subject would have been retaining nearly 30 $\mathrm{mEq}$. of potassium daily and could not have long survived under such circumstances. The fact that his serum potassium concentration did not rise during the two periods of observation suggests strongly that this extra component of tubular secretion of potassium was effective in maintaining potassium balance on this intake.

The attempt to block tubular secretion of potassium by administration of caronamide was completely unsuccessful as shown in Table II.

\section{DISCUSSION}

I. The validity of our observation of renal tubular secretion of potassium depends upon how truly the methods measure the functions under consideration. The possible errors in this study involve the use of the 24 hour endogenous creatinine clearance as a measure of glomerular filtrate volume and the use of the fasting serum potassium as a measure of the concentration of potassium in the glomerular filtrate ${ }^{3}$ throughout the 24 hour period. In subject $F$. W. the ratio of actual urine potassium excretion to that calculated to be present in the simultaneous volume of glomerular filtrate was about 2.0. Thus a total error of $100 \%$ in the measurements of glomerular filtration volume and serum potassium concentrations would be necessary to invalidate the observation. Furthermore, this error would have to be the result of the glomerular filtration rates being grossly too low, or the fasting serum potassium concentrations being markedly lower than the average serum potassium throughout the 24 hour period.

Because of our interest in measuring glomerular filtration rates in normal subjects and in patients with kidney disease over intervals of time that have physiological significance and without disturbing the usual activity of the subject, we have been utilizing the 24 hour clearance of endogenous "creatinine chromogen" as an index of this function. Smith (17) has reviewed the evidence

8 The Donnan correction and the correction for potassium concentration in serum water rather than in whole serum were both omitted. Being in opposite "directions" these corrections tend to cancel each other. against the use of the exogenous creatinine clearance as a measure of glomerular filtration volume and has pointed out that the exogenous creatinine clearance to inulin clearance ratio in man has been found to average 1.4. Inulin clearance is generally accepted today as the most accurate index of glomerular filtration rate. As stated, we have utilized endogenous creatinine clearance in this study.

Studies of Steinitz and Türkand (18) and more recently of Brod and Sirota (16) and of Hare et al. (19) have shown that the endogenous "creatinine" clearance measures essentially the same function as does inulin. Thus Brod and Sirota found that the ratio of the simultaneous clearances of endogenous creatinine chromogen to inulin averaged $1.00 \pm 0.018$ with a range of 0.88 to 1.10 in 94 measurements in normal subjects. In 57 simultaneous determinations of endogenous creatinine chromogen clearance and inulin clearance in 13 patients with nephritis, they found in 12 subjects a ratio of $1.04 \pm 0.109$ with a range of 0.89 to 1.25 . The sole large discrepancy gave a ratio of 1.61 apparently due to secretion of creatinine by the renal tubules. The patients in Brod's study who had filtration volumes reduced to the same degree as our patients showed creatinine to inulin clearance ratios of 1.16 and 1.15. In only four of the nephritic patients were filtration rates as measured by endogenous creatinine less than those obtained by inulin. The actual ratios of creatinine to inulin clearances in these cases were $0.89,0.92,0.94$ and 0.97 ; discrepancies too small to affect our results.

We have discussed these results of Brod and Sirota in some detail to indicate that when a discrepancy arises between the endogenous creatinine clearance and the simultaneous inulin clearance the significant differences are the result of higher creatinine clearances. Steinitz and Türkand (18) using a modification of the alkaline picrate method for creatinine determinations found creatinine to inulin clearance ratios uniformly greater than 1.0 in their nephritic subjects, though clearances were reduced to as low as $2.0 \mathrm{cc}$. per minute in some of their cases. Hare et al. (19) have very recently reinvestigated the validity of the endogenous creatinine clearance in renal insufficiency using their own improved modification of the alkaline picrate method. They also found endogenous creatinine clearances to exceed simultaneous inulin clearances in these subjects. 
We have utilized the same method for serum and urine "creatinine" analyses as that used by Brod and Sirota. As pointed out above only a measured filtration volume that would be grossly less than the true filtration volume would invalidate our observations, but the evidence presented indicates that if a difference between inulin and endogenous creatinine clearance occurs, it is caused by the latter giving higher results.

A final point regarding the use of the 24 hour endogenous creatinine clearance as a measure of glomerular filtration rate is the validity of calculating clearance from a single serum creatinine determination. It must be shown that the serum creatinine concentration remains constant throughout the clearance period. To settle definitely this question in our subject $\mathrm{F}$. W., serum creatinine concentrations were determined at intervals throughout a 24 hour period. Table III shows the insignificant degree of variation that actually occurred in the serum creatinine concentration of this patient.

The second source of error mentioned above relates to our use of a single fasting serum potassium as a measure of serum potassium concentration throughout the clearance period. It must be shown that its concentration remains constant throughout the clearance period. To settle this question definitely in our subject F. W., serum potassium concentrations were determined at intervals throughout a 24 hour period. Table III also shows that the variations that actually occurred in the serum potassium concentration of this patient were too small to affect the validity of our results.

We conclude that the evidence just cited establishes the validity of our observation. However, it is realized that all present methods of measuring glomerular filtration rates are based on indirect evidence. The possibility that creatinine may actually be reabsorbed by passive diffusion through the renal tubular epithelium of the severely damaged kidney cannot be absolutely excluded. The evidence cited above that the inulin clearance is usually slightly less than the creatinine clearance would be difficult to explain on the basis of such increased permeability of the renal tubular epithelium to creatinine. It would be very unlikely that the large inulin molecule would diffuse back through the tubular membrane more rapidly than the much smaller creatinine molecule. The observation that in severe chronic renal insufficiency the clearance of urea approximates that of creatinine (18) can best be explained by assuming a decreased reabsorption of urea (20). If the permeability of the tubular membrane were increased to permit a back diffusion of creatinine, an even larger than usual reabsorption of the smaller molecule of urea would be expected. This would increase rather than decrease the difference between urea and creatinine clearance.

II. The finding of renal tubular secretion of potassium in the presence of severe renal insufficiency raises the interesting question of whether normal kidneys also possess this ability. The usual quantities of potassium ingested do not strain the functional capacity of the normal kidney in excreting potassium. A normal individual in potassium balance excretes a quantity of potassium in the urine that is much less than the amount in the glomerular filtrate. To test the normal kidney for its capacity to secrete potassium by creating a need to eliminate potassium in amounts greater than those present in the glomerular filtrate might be hazard-

TABLE III

Blood urea nitrogen, serum creatinine and serum potassium concentrations in subject $F$. W. at intervals throughout a single 24 hour clearance period on 5/26/49

\begin{tabular}{|c|c|c|c|c|c|c|c|}
\hline & $\underset{(8: 30 \text { a.m. })}{\text { Fasting }}$ & $\begin{array}{c}90 \text { minutes } \\
\text { after breakfast } \\
(10: 20 \text { a.m. })\end{array}$ & $\begin{array}{l}\text { Before lunch } \\
(12: 10 \text { p.m. })\end{array}$ & $\begin{array}{l}120 \text { minutes } \\
\text { after lunch } \\
(2: 35 \text { p.m.) }\end{array}$ & $\begin{array}{l}\text { Before supper } \\
(5: 10 \text { p.m. })\end{array}$ & $\begin{array}{l}\text { Bed-time } \\
(9: 30 \text { p.m. })\end{array}$ & $\begin{array}{c}\text { Fasting follow- } \\
\text { ing morning } \\
(8: 30 \text { a.m. })\end{array}$ \\
\hline Blood urea nitrogen & 117 & 119 & 117 & 117 & 116 & 116 & 117 \\
\hline Serum creatinine & 11.2 & 11.2 & 11.1 & 11.3 & 11.2 & 11.1 & 11.2 \\
\hline $\begin{array}{c}\text { Serum potassium } \\
m E q . / \text { liter }\end{array}$ & 5.06 & 5.47 & 5.62 & 5.81 & 5.69 & 5.87 & 5.27 \\
\hline
\end{tabular}

The data show the constancy of these values. This establishes the validity of calculating the 24 hour clearances of these substances from their concentrations in a single fasting blood specimen. 
ous and we have not performed such experiments. A normal subject having a 24 hour glomerular filtrate volume of 150 liters and a serum potassium concentration of $5 \mathrm{mEq}$./liter would filter 750 $\mathrm{mEq}$. or about 29 grams of potassium daily. To increase the load requiring excretion significantly above this, it would be necessary to administer about 50 grams of potassium or 95 grams of the chloride salt daily to a normal subject! Administering hypertonic potassium solutions to normal subjects in the attempt to greatly increase the excretion of potassium for short periods has also seemed to entail considerable risk.

It would, however, be surprising to us if this tubular secretion of potassium in severe renal insufficiency were an entirely new function developed by the diseased renal tubules to preserve homeostasis in regard to potassium content of the body and prevent toxic accumulation of potassium in the body fluids. The demonstration by Mudge et al. (8) of renal tubular secretion of potassium during forced osmotic diuresis in dogs suggested to them that the excretion of potassium by the kidney normally involves renal tubular secretion of this substance but that this is masked under usual circumstances by an even larger increment of tubular reabsorption. Thus, when the diuresis produced was so great that over half the volume of the glomerular filtrate was excreted, there was no time for the usual large percentile reabsorption of potassium and the tubular secretion of potassium then became manifest. In our patients with greatly reduced glomerular filtration rates, a usual urine volume of 1 to 2 liters in 24 hours likewise represents a very sizeable fraction of the filtrate volume.

It is interesting in this connection to compare the behavior of the diseased kidney in its excretion of urea and potassium. In the normal subject under usual circumstances both are excreted at urine concentrations greatly exceeding their serum concentrations and, in addition, the total quantity of each in the urine is regularly less than the large amount in the glomerular filtrate. But as disease destroys functional renal tissue and glomerular filtration rate becomes reduced, urea is gradually retained in the body fluids in increasing concentration. Within the relatively narrow limits of variation in the percentage of filtered urea reabsorbed by the renal tubules, the concentration of urea in the blood is defined only by the glomerular filtration rate and the quantity of urea liberated in the body from protein catabolism (20). Several studies $(18,21,22)$ have shown that even with the severest renal disease the quantity of urea excreted does not exceed that filtered through the glomeruli. With potassium, on the other hand, the effect of reduced glomerular filtrate volume is in part mitigated by at least this one mechanism we have described. This mechanism operated with sufficient exactness in subject $F$. W. to preserve the serum potassium at a perfectly normal concentration in spite of the very low filtrate volumes. This ability of the damaged kidney apparently to distinguish between one substance, urea, which is innocuous and allowed passively to accumulate in the body fluids and another substance, potassium, whose accumulation would be rapidly lethal and which is actively secreted by the tubules of the failing kidney, seems to us a remarkable example of the "wisdom" of the body. On the other hand, the fact that this mechanism was also operating to contribute to a deficit in body potassium in subject F. W., at a time when his serum potassium was subnormal, indicates that this "regulation" is less than perfect.

\section{CONCLUSIONS}

Data are presented to show that potassium is actively secreted by the renal tubules of man. This was demonstrated in several persons suffering from far advanced renal insufficiency. This tubular secretion of potassium acted as a mechanism preventing toxic accumulation of potassium in the body fluids of these cases; however, it also contributed to a deficiency of body potassium in some instances.

\section{ACKNOWLEDGMENT}

The authors wish gratefully to acknowledge their appreciation to Dr. L. H. Newburgh whose interest and wise guidance made this study possible.

\section{CASE HISTORIES}

(1) H. R., University of Michigan Hospital No. 649823. This 44 year old white male was first admitted to University Hospital on November 12, 1948 complaining of anorexia, ease of fatigue, irritability and drowsiness since April, 1948. Episodes of palpitation, angina pectoris, and dyspnea began in July, 1948. Fourteen 
years before admission he was told that he had hypertention and albuminuria but he was asymptomatic during this interim. Examination on admission revealed a lethargic, dehydrated male with a uriniferous odor to his breath. Blood pressure was 180/95. Fundi showed blurring of the discs, increased reflex stripes, A-V nicking, tortuosity and spasm of the vessels with hemorrhages and exudates into the retina. The heart was enlarged and the liver was palpable $3 \mathrm{~cm}$. below the right costal margin. Urinalysis revealed albumin, red cells, casts, and a low fixed specific gravity. The non-proteinnitrogen was $253 \mathrm{mgs} . / 100 \mathrm{cc}$. and blood urea nitrogen $137 \mathrm{mgs} / 100 \mathrm{cc}$. The diagnoses of chronic glomerulonephritis with severe renal insufficiency, and arteriosclerotic and hypertensive heart disease with angina pectoris were made. The patient was treated with a diet containing 40 grams of protein and supplementary sodium chloride. He was discharged home but returned after 10 days because of increase in chest pain, a cough productive of bloody sputum, chills, fever, and ankle edema associated with a 10 pound gain in weight. On his second admission on December 13, 1948, he was found to be acutely ill with a temperature of 101.8 and moist rales at both lung bases. The fever responded to penicillin; however, the renal insufficiency progressed and the patient died in uremia on January 28, 1949. The pathological diagnoses were: Advanced, active, chronic glomerulotubular nephritis, chronic, purulent, cysto-ureteropyelitis with patchy pyohydronephrotic atrophy and sclerosis. Advanced generalized atherosclerosis with coronary occlusive disease and old infarcts of posterior wall and papillar muscles of left ventricle.

(2) D. M., University of Michigan Hospital, No. 654317. This 39 year old white male was admitted to University Hospital on February 3, 1949 because of marked weakness and pain in the right flank. He was well until 10 days prior to admission when he had onset of the right flank pain which was dull and constant. No urinary symptoms accompanied this pain, but he noted weakness and tiredness. About a week later he became nauseated and vomited many times, being unable to keep down any food. No past history of kidney or urinary tract disease and no family history of kidney disease were obtained. Physical examination on admission revealed a well developed male appearing dehydrated and lethargic. Blood pressure was $146 / 78$. Some abdominal distention was present and the patient had a large indirect left inguinal hernia. Otherwise the examination was negative. The urine showed persistent albuminuria, a low, fixed specific gravity, none or few red cells, occasional pus cells and no casts, but cocci and bacilli were repeatedly found. The non-protein-nitrogen was $227 \mathrm{mgs}$./ $100 \mathrm{cc}$. and the $\mathrm{CO}_{2}$ combining power 22 vols. $/ 100 \mathrm{cc}$. on admission. The serum chloride was $96 \mathrm{mEq}$./liter, the serum calcium $4.1 \mathrm{mgs} . / 100 \mathrm{cc}$. and the serum creatinine $13.4 \mathrm{mgs} . / 100 \mathrm{cc}$. The hemoglobin was $12.8 \mathrm{grams} /$ $100 \mathrm{cc}$. and the Kahn test was negative. The patient was treated with intravenous fluids containing glucose, sodium chloride, sodium lactate and potassium chloride with rather surprising improvement in his clinical condition.
Retrograde pyelograms were done and were interpreted as suggesting polycystic kidney disease with superimposed pyelonephritis. The serum potassium on February 12th after 9.0 grams of intravenous potassium chloride was $3.15 \mathrm{mEq}$./liter. As the patient's condition improved and the non-protein-nitrogen concentration dropped to $108 \mathrm{mgs} . / 100 \mathrm{cc}$., his nausea disappeared and he started taking food. His diet was supplemented with 12 grams of potassium bicarbonate daily prior to the reported study. This was discontinued when the serum concentration was found to be high. He continued to improve, was discharged home, and at last report was gradually resuming his work.

(3) D. P., University of Michigan Hospital No. 560425. This 37 year old white female was first seen at University Hospital on December 7, 1944 because of massive edema and hypertension. She had been well until May, 1944, when, following a sore throat, she first noticed puffiness of hands and face. During the next few months she gained 40 pounds in weight and noted occipital headaches, blurring of vision and urinary frequency. No gross hematuria was noted. Physical examination on this admission revealed a blood pressure of $178 / 92$, and generalized anasarca. Urinalysis showed albumin, red blood cells, granular casts and a fixed specific gravity of 1.011 during a concentration test. The red blood cell count was 2.9 million with a hemoglobin of 8.0 grams $/ 100 \mathrm{cc}$. Kahn test was negative. Blood urea nitrogen was $11 \mathrm{mgs} . / 100 \mathrm{cc}$. Total serum proteins were 4.2 grams with an albumin/globulin ratio of 1.1 . The urea clearance showed $19 \%$ of normal function. The blood cholesterol was $533 \mathrm{mgs}$./100 cc. A diagnosis of chronic glomerulonephritis with nephrotic syndrome was made, the patient was treated with a diet containing 40 grams of protein and $300 \mathrm{mgs}$. of sodium. On this regime her weight slowly returned to normal as her edema disappeared.

She has been seen repeatedly since the first admission, showing a gradual progression of her disease with gradual increase in uremia, the blood urea rising to 72 mgs./100 cc. and the serum creatinine to $8.8 \mathrm{mgs} . / 100 \mathrm{cc}$. The inulin clearance averaged $12 \mathrm{cc}$./minute in February, 1948. Anemia has been persistent with a hematocrit averaging $23 \%$. The blood pressure gradually has risen to 190-210 systolic and 90-120 diastolic and the patient has developed cardiomegaly, orthopnea, and marked shortness of breath with exertion. Moderate sodium restriction is still required to prevent edema formation although total serum proteins have risen to $6.5 \mathrm{grams} /$ $100 \mathrm{cc}$. Urinalyses continue to show albumin, red cells and casts.

(4) F. W., University of Michigan Hospital No. 626991. This 29 year old male was first admitted to University Hospital in November, 1947 because of headaches and blurring of vision. At the age of 18 marked albuminuria was found on routine examination. The patient had no symptoms at that time and no history of earlier renal disease. At the age of 20 he began to have dull aching headaches, often occipital in location, which have become more frequent. $\mathrm{He}$ was told then that he 
had high blood pressure. With this he has noted weakness, ease of fatigue, frequency and nocturia, some blurring of vision, nausea, and vomiting. Gross hematuria or dysuria have not been present.

On occasions over the three years prior to his admission he has noted transient episodes of pitting edema of lower extremities after being up and about for some time. There was no history of generalized edema. Physical examination on admission revealed a well developed and well nourished male appearing pale and chronically ill. Blood pressure was 210/150. Fundi showed papilledema, angiospasm, hemorrhages and exudates in both eyes. The heart was enlarged, urinalysis showed albumin, red cells and casts. The Kahn test was negative. The red cell count was 2.8 million and the hemoglobin 10 grams/ $100 \mathrm{cc}$. The non-protein-nitrogen was $68 \mathrm{mgs} / 100 \mathrm{cc}$. Total serum proteins were $4.4 \mathrm{grams} / 100 \mathrm{cc}$. with an A/G ratio of 2.1 . The urea clearance was $18 \%$ of normal and the inulin clearance in March, 1948 averaged $13.0 \mathrm{cc} . /$ minute. The diagnosis of chronic glomerulonephritis with hypertension and hypertensive heart disease was made.

The patient has had many readmissions to this Hospital, each time showing progression of his renal and vascular disease. His last admission was on June 8, 1949 because of congestive heart failure. Latest studies revealed the systolic blood pressure to remain over 200 $\mathrm{mm}$. There has occurred marked wasting. Ascitic and pleural fluid was present necessitating paracentesis and thoracentesis. The non-protein-nitrogen has risen to $190 \mathrm{mgs} . / 100 \mathrm{cc}$. and the urea clearance has fallen to $6.3 \%$ of normal.

\section{BIBLIOGRAPHY}

1. Keith, N. M., and Osterberg, A. E., The tolerance for potassium in severe renal insufficiency: a study of ten cases. J. Clin. Invest., 1947, 26, 773.

2. Wilkins, L., and Kramer, B., Studies on the potassium content of human serum. Arch. Int. Med., 1923, 31, 916.

3. Elkinton, J. R., Tarail, R., and Peters, J. P., Transfers of potassium in renal insufficiency. $\mathrm{J}$. Clin. Invest., 1949, 28, 378.

4. Keith, N. M., King, H. E., and Osterberg, A. E., Serum concentration and renal clearance of potassium in severe renal insufficiency in man. Arch. Int. Med., 1943, 71, 675.

5. Keith, N. M., Osterberg, A. E., and Burchell, H. B., Some effects of potassium salts in man. Ann. Int. Med., 1942, 16, 879.

6. Leaf, A., and Couter, W. T., Evidence that renal sodium excretion by normal human subjects is regulated by adrenal cortical activity. J. Clin. Invest., 1949, 28, 1067.

7. Berliner, R. W., and Kennedy, T. J., Jr., Renal tubular secretion of potassium in the normal dog. Proc. Soc. Exper. Biol. \& Med., 1948, 67, 542.

8. Mudge, G. H., Foulks, J., and Gilman, A., The renal excretion of potassium. Proc. Soc. Exper. Biol. \& Med., 1948, 67, 545.

9. McCance, R. A., and Widdowson, E. M., Alkalosis with disordered kidney functions. Lancet, 1937, 2, 247.

10. McCance, R. A., and Widdowson, E. M., The Chemical Composition of Foods. Chemical Publishing Co., Inc., New York, 1947.

11. Shohl, A. T., and Bennett, H. B., A micro method for the determination of potassium as iodoplatinate. J. Biol. Chem., 1928, 78, 643.

12. Berry, J. W., Chappell, D. G., and Barnes, R. B., Improved method of flame photometry. Indust. \& Engin. Chem., Analyt. Ed., 1946, 18, 19.

13. Bonsnes, R. W., and Taussky, H. H., On the colorimetric determination of creatinine by the Jaffe reaction. J. Biol. Chem., 1945, 158, 581.

14. Hare, R. S., and Hare, K., Determination of creatine in blood and urine. Federation Proc., 1949, 8, 68.

15. Beyer, K. N., Russo, H. F., Patch, E. A., Tillson, E. K., and Shaner, G., Certain pharmacologic properties of 4'-carboxyphenylmethanesulfonanilide (caronamide) including its effects on the renal clearance of compounds other than penicillin. J. Pharmacol. \& Exper. Therap., 1947, 91, 272.

16. Brod, J., and Sirota, J. H., The renal clearance of endogenous "creatinine" in man. J. Clin. Invest., 1948, 27, 645.

17. Smith, H. W., The Physiology of the Kidney. Oxford University Press, New York, 1937.

18. Steinitz, K., and Türkand, H., The determination of the glomerular filtration by the endogenous creatinine clearance. J. Clin. Invest., 1940, 19, 285.

19. Hare, K., Goldstein, H., Barnett, H. L., McNamara, H., and Hare, R. S., Renal excretion of creatinine in man. Federation Proc., 1949, 8, 67.

20. Leaf, A., and Camara, A. A., A further evaluation of the factors that determine the concentration of blood urea in man. Unpublished.

21. Chasis, H., and Smith, H. W., The excretion of urea in normal man and in subjects with glomerulonephritis. J. Clin. Invest., 1938, 17, 347.

22. Corcoran, A. C., and Page, I. H., Differential diagnosis of terminal glomerulonephritis and malignant hypertension. I. Renal aspects. Ann. Int. Med., 1944, 21, 747. 